\title{
Construction of cubature formula for double integration with algebraic singularity by spline polynomial
}

\begin{abstract}

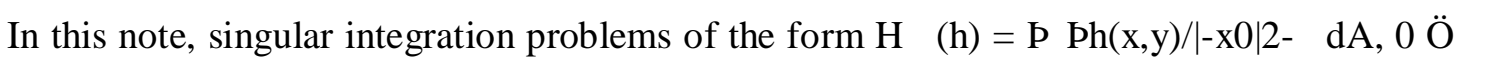
Ò 1 , where $\mathrm{q}=[\mathrm{x} 0, \mathrm{y} 0] \times[\mathrm{b} 1, \mathrm{~b} 2], \mathrm{x}=(\mathrm{x}, \mathrm{y})$; $\mathrm{q}$ and fixed point $\mathrm{x} 0=(\mathrm{x} 0, \mathrm{y} 0)$; $\mathrm{q}$ is considered. The density function $\mathrm{h}(\mathrm{x}, \mathrm{y})$ is assumed given, continuous and smooth on the rectangle $q$ and belong to the class of functions $\mathrm{C} 2, \breve{U}(q)$. Cubature formula for double integrals with algebraic singularity on a rectangle is constructed using the modified spline function $\mathrm{Sq}(\mathrm{P})$ of type $(0,2)$. Highly accurate numerical results for the proposed method is given for both tested density function $\mathrm{h}(\mathrm{x}, \mathrm{y})$ as linear, quadratic and absolute value functions. The results are in line with the theoretical findings.
\end{abstract}

Keyword: Cubature formula; Double integration; Algebraic singularity; Spline polynomial 